\title{
REFLEXIVITY, THE SOCIAL ACTOR, AND M-SERVICE DOMESTICATION: Linking the Human, Technological, and Contextual
}

\author{
Jennifer Blechar \\ University of Oslo \\ Oslo, Norway \\ Lars Knutsen \\ Jan Damsgaard \\ Copenhagen Business School \\ Copenhagen, Denmark
}

\begin{abstract}
The importance of understanding the factors impacting technology acceptance is well emphasized. However, technology acceptance research is primarily oriented to the individual level in which users or consumers are treated as actors typically making one-way adoption or rejection decisions related to the acceptance of new technology. In this article, we argue that such research stops short of acknowledging the influence of agents' social monitoring of own and other's behavior. By leaning on the process of stratification and the construct of reflexivity, as applied by Giddens (1984), and coupling this with the view that humans are social actors reflexively engaged in the domestication of new technologies, we present the initial progress toward a process model that may guide our understanding of how potential and existing users of new mobile data services learn, draw upon previous and emerging experiences, and thereby bring, or do not bring, new $m$-services into the performance of everyday practices. Based on the results from our field study, this paper suggests that re-projecting previous experience and reflexivity considerably influences cognition and action in the duration of m-service domestication, thereby bringing complementary understanding to current technology acceptance research.
\end{abstract}

Keywords Domestication, reflexivity, acceptance, adoption, mobile services 


\section{INTRODUCTION}

Adoption and diffusion of innovations theories have for more than half a century been the principal anchors in providing guidance and comprehension of how innovations are generated and evolve as well as how they diffuse and become adopted in populations (Gopalakrishnan and Damanpour 1997; Rogers 2003). Moreover, variance-oriented technology acceptance research has emerged from cognitive-oriented marketing research into technology studies, both in mandatory and voluntaristic technology use domains, to explain and predict attitudes, intention to use, and eventual use of new technologies (Foxall et al. 1998; Venkatesh et al. 2003). Both genres of research have provided a significant and fundamental level of understanding of technology acceptance and use.

However, the compound nature of wireless services (Knutsen and Overby 2004) as well as their multifaceted characteristics, challenge the ability to define specific items or variables related to the particular material or virtual artifact in question. Thus, while technology acceptance research has focused on identifying and determining general impacts of categorical variables (such as ease of use, usefulness, etc.) on technology acceptance and use, the very general nature of these characteristics may render them inappropriate or even work as blinders for exploring the specifics of the artifact and the potentially important alterations emerging during the process of technology acceptance.

Acceptance and use of wireless services can be far messier, more complex, and more ambiguous than nomothetic perspectives of technology acceptance generally convey. Just as scholars of the Austrian School of Economics contend that pure profit opportunities "can not be object to systematic search" because they are unknown until discovered (Kirzner 1997, p. 71), intentions, expectations, and eventual use of wireless services can prove impossible to comprehend and predict until developed, experienced, interpreted, and somewhat incorporated into the everyday lives of users. Thus, before user engagement in the domestication ${ }^{1}$ process - the process of adopting and imbedding a product or service into everyday life (Lehtonen 2003; Lie and Sørensen 1996; Ling 2004; Ling and Haddon 2001; Silverstone and Haddon 1996) the possibilities of understanding potential user cognizance and behavior related to technology acceptance is likely to be nebulous, porous, and amorphous.

Understanding consumer practices related to the acceptance and adoption of new products and services, therefore, needs to be derived in relation to the potential reciprocal impact integration with life practices, as well as the emergence of new practices, might have on acceptance, adoption, and diffusion. This is particularly significant for wireless services as the domestication of a distinct artifact in question may depend upon the consumption of other material and virtual artifacts and their associated properties. For instance, whereas mobile phones have diffused with unprecedented pace and become the most omnipresent and widely deployed communications

'Despite etymological connotation to the home sphere and the taming and modification of the wild to domestically fit human needs, domestication has entered technology studies to signify how new technologies enter spheres of everyday social life - in and outside the home - and how meaning is constructed and reconstructed during careers (Haddon 2001, 2004; Lie and Sørensen 1996). 
technology in the world (Nokia 2003) and the adoption of voice and text ${ }^{2}$ services have unfolded as social epidemics, we see that acceptance and adoption of gateway and mobile Internet services have not reached such tipping points in most of the Western world.

The goal of this article is to outline a framework that can enable enhanced first(subjective) and second-level (interpretive) understanding (see Lee 1991) of wireless service domestication. We start by reviewing existing acceptance and adoption research. Finding limitations in capturing and explaining changes caused by reflexivity over own and others mobile service actions in the unfolding of domestication, we develop a framework to guide the discussion of our subsequent interpretive inquiry by merging two streams of hitherto disconnected theories: the stratification framework of Giddens (1984) and the domestication approach advocated by Silverstone and Haddon (1996), including recent extensions to this approach (Ling 2004; Ling and Haddon 2001). The results of our research suggest that an analysis of actors' reflexive monitoring of m-service actions can complement technology acceptance research by revealing idiographic accounts of centrally influencing reference technologies impacting the progression of the wireless service domestication process.

\section{TECHNOLOGY ACCEPTANCE AND ADOPTION}

A large variety of theories and models have been developed, conceptualized, operationalized, and empirically supported with the aim of contingently determining and predicting user actions related to decisions to accept and adopt new technology. Among the most influential are those with roots in the theory of reasoned action (TRA) (Ajzen and Fishbein 1980) such as the theory of planned behavior (TPB) (Ajzen 1985 1991), the technology acceptance model (TAM) (Davis 1989), and the decomposed theory of planned behavior (Taylor and Todd 1995). Resulting from the variety of different constructs proposed, Venkatesh and colleagues (2003) more recently joined root constructs discussed in previous research into the four main latent variables of performance expectancy, effort expectancy, social influence, and facilitating conditions.

In the mobile arena, several of the constructs and relations found in technology acceptance models have been adopted, adapted, and used to predict user behavior and investigate acceptance (see Khalifa and Cheng 2002; Lu et al. 2003; Pedersen and Ling 2003). However, as has been illustrated by Knutsen (2005), the inflexible nature of such models make them, which is also outside their scope, inapplicable for the purposes of obtaining a deeper understanding of the often multifaceted set of emerging idiosyncrasies transpiring and becoming formed as novel artifacts, or sets of artifacts, permeate the life-worlds of users. Thus, while existing research has been attentive to elements such as current and past experience (i.e., Hubona and Burton-Jones 2003), this work has not explored the evolution of artifacts prior and subsequent to the absolute points of acceptance and adoption; the further socio-technical molding of the artifact.

\footnotetext{
${ }^{2}$ This includes SMS (primarily in GSM areas) as well as mobile e-mail (primarily in Japan and the United States).
} 
Moreover, as these models are directed at the individual level, items such as social influence are treated strictly from the relative social "pressure" the potential accepter may perceive (i.e., Venkatesh et al. 2003). Thus, although technology acceptance scholars acknowledge that human actors exist and act within, often particularly clearly defined, social contexts (usually organizational contexts), less attention seems directed toward the influence that previous as well as emerging experiences with technologies might have on existing knowledge and, thus, users' interpretations and the social aspects therein. In fact, the orientation toward prediction in technology acceptance research discards dynamism and thus dialectical changes in (potential) users' knowledgeability concerning technology.

Limitations to diffusion of innovations theory and technology acceptance research have been pointed out (Lyytinen and Damsgaard 2001; Rogers 1995; Van de Ven and Rogers 1988; Wolfe 1994). Interestingly, Venkatesh et al. (p. 470), although maintaining a stringent positivist orientation, encourage researchers to undertake efforts to reach a "richer understanding of technology adoption," which can offer improved guidance to designers of technology. However, this presupposes a technological clarity at the user side that may not exist, or exist only illusorily or nebulously. As Miller (1987, p. 103) contends, "whereas the artefact appears to offer the clarity of realism... which is quite illusory...the object is as likely as the word to evoke variable responses and invite variety of interpretations." Therefore, in order to offer guidance to designers, it is a prerequisite that users have an idea of the designers' technology spirit (DeSanctis and Poole 1994) and the intentions underlying the design of the technology, so that this can be explicated beyond imaginary use and involve more than just an excavated trench of more or less connected juxtapositions. For this, specificity of the properties of the artifact, the product, or the service, beyond general expectations of relative advantage, ease of use, performance expectancies, etc., is needed; specificity is only obtainable as the artifact establishes its meaning through use (Rohracher 2003).

In exploratory technology settings, as for m-services, it may be advantageous to observe Rogers' (1995) encouragement to move research frontiers toward behavioral and social learning aspects of innovation and, more specifically, pay tribute to how overt behavioral changes unfold over time. Although several suggestions have partly accommodated this, for example by calling for closer integration between diffusion of innovations theory, technology acceptance, and domestication (Pedersen and Ling 2003; Pedersen et al. 2002), most research is still at a conceptual rather than empirical level. Despite gains toward more interactive process views, consideration of the malleability caused by actors' cognitive reflection over engagement with $\mathrm{m}$-services or social cues reflecting $\mathrm{m}$-services during the domestication process have, to our awareness, not been under scrutiny. We argue that an alternative approach, which we now turn to present, can bring about such understanding and thereby complement technology acceptance research.

\section{REFLEXIVITY AND THE SOCIAL AC'TOR: A PROCESS MODEL}

Social constructivist approaches have strongly aided in overcoming technological determinism, the idea that technology unidirectionally shapes society, by highlighting 
social aspects of technology creation, use, and the double hermeneutics of sociotechnical impacts. This has occurred from the perspective of influences of user interpretations on the evolution of technology (Pinch and Bijker 1987), and from the constantly fluctuating influence of actors, including living agents and nonorganic objects, within a system (Hughes 1987). In these approaches, users are viewed as constantly negotiating and renegotiating their respective meaning of artifacts, hereunder products and services, shaping and being shaped by them in various ways until closure or stabilization is considered to finally be reached (Pinch and Bijker 1987: 44). Although the relative structuring capabilities of nonorganic agents and the notion of closure are contestable (is closure ever reached?), the acknowledgement of degrees of circularity and reciprocity between technology and social actors is important because it recognizes that technology has a life beyond the state of acceptance and adoption, and that as technology molds interpretations, current interpretive schemes will also mold the interpretation of technology, thus pointing to the social manifestation of emerging technologies.

The above perspective enables the consideration of users as social actors (Lamb and Kling 2003). Despite their focus on actors in organizations, whereas we focus on $\mathrm{m}$ service use in voluntaristic contexts, we concur with Lamb and Kling that in order to understand information systems use beyond laboratory and context insensitive settings, the thin user concept in information systems research needs to embrace a conceptualization of users as social actors. This includes acknowledging that users have social affiliations and can represent larger social-entities through their actions, can influence and be influenced by their environments, engage in interactions that can exert as well as take on influence from and by the social as well as technological, and that identities are expressed as well as shaped through the interactions with technology and other social actors (Lamb and Kling 2003).

If accepting that technology (i.e., m-services) is both a mediator of as well as mediated by practice, emphasis needs to be placed on current socio-technical practices and those emerging in relation to new technology, the contexts in which they occur, and what they socially symbolize. Since practices are enabled and constrained by the actors ${ }^{33}$ knowledgeability - knowledge of actors and their ability to act upon tacit and discursively available knowledge (Giddens 1984) - it is also necessary to understand how knowledgeability of new technology develops. Because knowledgeability is likely to develop with a basis in, and sometimes even challenge, the foundation of what is currently known and instantiated in practice (i.e., current practices with technologies and previous experiences), it seems promising to focus on what Giddens expresses as stratification of action.

In the stratification model, Giddens emphasizes that humans are not only constantly monitoring their own action, but also the actions of others in the "monitored character of the ongoing flow of social life" (p. 3). In this way, stratification of action involves the embedded processes of reflexive monitoring of action occurring within interpretable contexts and human rationalization as well as motivation of action. Thus, the reflexive monitoring of daily life is considered the foundation of the recursive ordering of social

${ }^{3}$ Giddens uses the term agent rather than actor. To avoid terminological confusion, the term actor is used in this paper. Interested readers are directed to Giddens (1984, pp. 20-30). 
practices across time and space in which routines preserve the current, while deviation from routines, in the form of unanticipated consequences of action, can cause emergence of new practices. In the presence of unintended consequences of own and others' actions, therefore, it is likely that social cues of the action can be picked up and be fed into the reflexive monitoring and thus impact future action decisions. According to Giddens, there is a cyclical relationship from peoples' actions to unintended consequences to unacknowledged conditions of these actions, all of which, if recurring over time and space, can reconstruct or promote and inaugurate new social structures which, through actors' reflexive monitoring, can influence future actions.

Interestingly, we have identified that the reflexive nature of human beings and our relations with technology are also central in the work on domestication of technology (Haddon 2001; Lehtonen 2003; Lie and Sørensen 1996; Ling 2004; Ling and Haddon 2001; Silverstone and Haddon 1996). For instance Aune (1996:91-92), sees domestication figuratively as "to handle something alien in such a way that it is adapted to your everyday life, and your everyday life is adapted to this new and hitherto alien artifact" and that this is a "two-way process in which both technology and humans are affected, and in which both technical and social features are changed." Silverstone and Haddon (1996), Aune (1996), and Ling (2004) all illustrate the domestication process to evolve through four or five interrelated phases or steps. ${ }^{4}$ These encompass, as illustrated in Figure 1, imagination, appropriation, objectification, incorporation, and conversion.

Succinctly put, imagination involves the removal of ignorance and/or the awakening of awareness and imagery concerning a new innovation such as a new mobile service or other technology. It is anticipated to develop from an arousal of previously unacknowledged socio-technical opportunities that trigger intuitive and interpretive processes. Although rejection and halt to the progression can occur at any time, imagination can lead to appropriation, the development of knowledge of the innovation to the state where procurement is a substantial possibility or actually occurs. It also symbolizes the step in which an innovation leaves the commercial sphere and enters our sphere of objects (Ling 2004).

Following (ideally) appropriation, objectification denotes the cognizance of how an innovation will fit into our world of objects; essentially, depictions and crystallizations of what identity cues we signal through our consumption and use of the technology (Ling 2004; Silverstone and Haddon 1996). Incorporation can follow, encompassing the process in which the technology (i.e., an m-service) is incorporated with and becomes part of our routines of everyday life. Finally, conversion describes the subprocess in the cycle where instantiations of technology represented through our socio-technical practices "become elements in others' estimation of us" (Ling 2004, p. 30) in various social groups. All of these phases involve the users or consumers making situated and reflexive actions or decisions regarding the new technology in their everyday lives.

By combining the above with the work of Giddens and adapting this to the realm of technology, we construct a process model to illustrate the reflexive nature of how

${ }^{4}$ The word steps is used illustratively to signify that there ideally, if admitting to a little proinnovation bias, is a degree of linear progression in the characteristic stages. This progression, however, may not always be as linear as portrayed. Rather it may be messy with several feedback loops and feedback as well as feed-forward step skipping. 


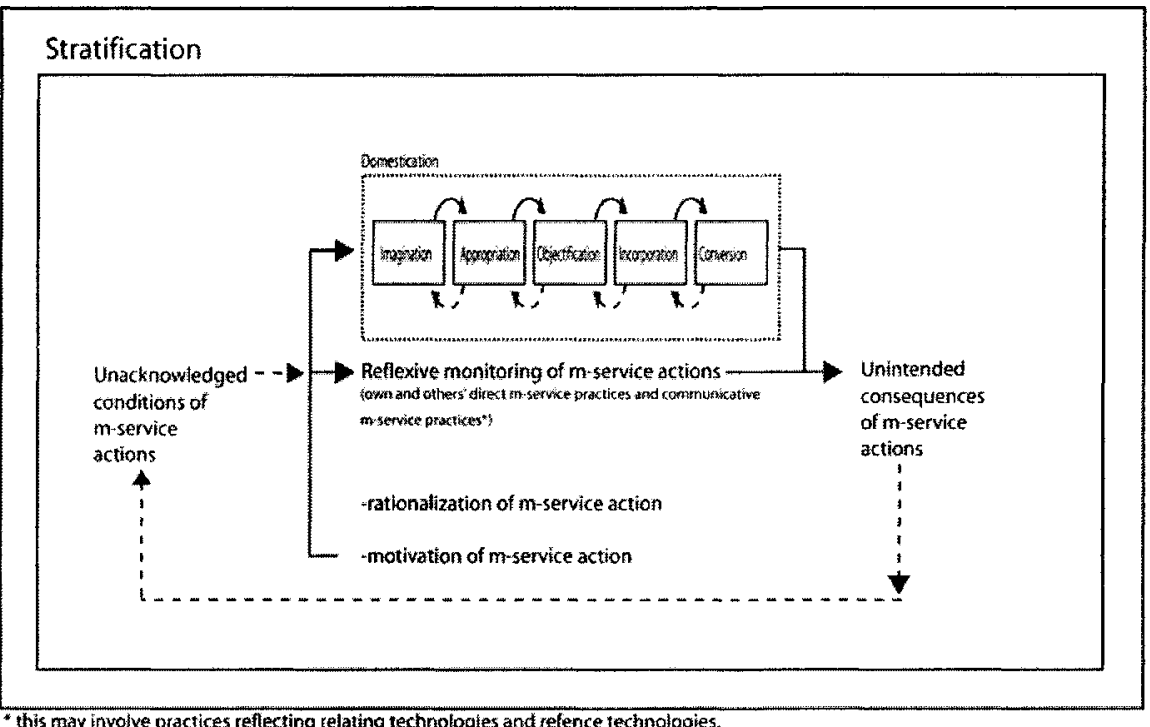

this may involve practices reflecting velating technologles and refence technologies.

Figure 1. Stratification in the Process of M-Service Domestication. Adapted and from Giddens (1984) and Silverstone and Haddon (1996)

actors actively engage in acceptance and adoption of new technology over time (see Figure 1). In the figure, the stratification process of Giddens is considered to produce as well as take on directions from the domestication process and its progression; stratification is linked reciprocally to the steps in the domestication process.

The process model illustrates how user actions, as instantiations of their interpretations related to the acceptance of new technology, are conceived to evolve and are influenced by previous actions and their possible unintended consequences and unacknowledged conditions. This process model highlights the importance of the reflexivity of peoples' actions and the manner in which users are continuously monitoring both their own and others' practices concerning m-services. While existing theories and models of technology acceptance view users as making primarily one-way action decisions influenced by various constructs, the proposed process model instead illustrates the potential evolving considerations users can place on previous actions and on current routines and their outcomes in their constant renegotiation of the technology within the overall evolving technology domestication process.

This model also emphasizes that the reflexive monitoring of own and others' actions in relation to a technology can both conform with as well as deviate from what is anticipated. Such deviations can lead to unfaithful appropriations (DeSanctis and Poole $1994)$ and, as originally proposed by Fichman and Kemerer $(1997,1999)$, yield macrolevel assimilation gaps: differences between cumulative patterns of technology acquisitions versus patterns of deployment. However, rather than focusing on cumulative patterns, the process model attends to the micro and mezzo level negotiations and 
renegotiations arising (relative to the degree of unfamiliarity) from users reflexive monitoring during the acquaintance with new m-services. Thus, with reflexivity underlying the domestication process, it opens for understanding how cognizance and practice development with respect to m-services (or other technologies) can alter during any typical stage, affecting the progression and directionality of the process, or even bringing the domestication and thus the technology acceptance process to a halt.

\section{A FIELD STUDY OF M-SERVICE DOMESTICATION}

The study reported in this paper was conducted in Denmark in the spring of 2004 and was undertaken in close collaboration with a mobile operator, device manufacturer, and several content providers. State of the art mobile phones with prepaid SIM cards ${ }^{5}$ were distributed to 38 users, providing access to a variety of gateway based m-services (e.g., news, entertainment, e-mail, downloading multimedia content, chat, dating, location-based services, information on contemporary events, etc.). Participants were selected based upon three criteria: (1) they belonged to socio-demographic groups suggested to be among the early adopters of new m-services-students and young professionals (Constantiou et al. 2004), (2) they were members of social or work groups in which social interaction was frequent and monitoring of m-service practices was possible both in the form of physical and virtual co-presence; and (3) they had interest in, but marginal to no mobile data service experience prior to joining the project. The average age of participants was 29 and 43 percent were females.

Data was collected from participants through a variety of qualitative and quantitative methods including surveys, interviews and group interviews. Surveys consisted of both open-ended and fixed response questions and were distributed to participants before, during and after the project period. Open-ended questions in the surveys were based on typical categories previously identified in the technology acceptance literature such as performance expectancy (In what ways can new mobile data services contribute and be useful in your everyday life?) and effort expectancy (How would you describe the efforts you need to make in order to use new mobile data services?). At the end of the project the participants were asked to describe functions and services that best supported their everyday practices, as well as the most important criteria mobile services should meet to provide value in their everyday life. Importantly, questions were not, at any time, framed in a way so that related technologies were mentioned, and not in a way asking the participants to actively report on how they contemplated about past and emerging experience with new m-services. Rather, we targeted our inquiry toward issues concerning performance, efforts, social influence, attitudes, etc. As such, a body of textual data subject for interpretation was gained.

Data analysis for the qualitative data followed Miles and Huberman's (1994) coding procedures. First the respondents' answers to the questions were partitioned based on

${ }^{5}$ The prepaid SIM cards provided a budget constraint of 250 DKK per month per user during the project. 
descriptive codes guided by a start-list derived from the theoretical model previously presented. Second, to explore patterns, we supplied pattern codes and placed the data into a clustered summary table. Following the clustering, the key findings were extracted and illustrative examples were chosen.

\subsection{Results and Discussion}

From our analysis we choose to focus on two issues relevant for the theoretical discussion of this paper. This includes what we have registered as a re-projecting of the participants' Internet experience and reflexive monitoring of $\mathrm{m}$-service practices.

\subsubsection{Re-projecting Internet Experience}

During the study, participants appear to have reflexively drawn upon their experience with the Internet when constructing their expectancies, both related to performance and effort, of new mobile services as m-service experience accrued. Although this should not be surprising, it is important with respect to complementing acceptance models as these cannot be utilized for understanding how expectancies are formed when artifacts are introduced. We registered that imagery of $m$-services before trial rotated around services already available on the regular Internet.

Many of the services I can envision use of on the mobile are already similar to those I use on the net: e-mail, news, yellow pages, directions, maps, route information and transport information. (Male, 22, before trial)

However, once participants learned the specific efforts and performances of the mservices, this created an assimilation gap as experience emerged which, to a large degree, lead users to become former users or dropouts. Whereas performance and ease were taken for granted before the m-service trial, unexpected or unintended consequences triggered reflexivity over their own and others' experiences and made participants ultimately alter their rationale for engaging in further domestication behavior.

I thought I would need and use similar services that I use on the net, but I now see that mobile services need to be developed so they serve a mobile setting and take the limitations of mobile phones into account. Annoyed that it still works like a modem on the computer, I turn to the net instead. (Male, 22, after trial)

It is not only when evaluating the usefulness or potential benefits that we see such re-projecting of Internet experience occurs. Through our analysis, we witnessed that participants experience from using the Internet moderated expectancies not only prior to trial but at process stages such as imagination, objectification, and incorporation, and that this re-projecting together with experience gained with new mobile data services fostered correspondence as well as digression from the idealized domestication process. The following quote illustrates not only how expectations changed, but also provide 
indications that expectancies and motivations were moderated through rationalization over m-service actions:

Internet was impressing as you did not have any other possibilities. But the mobile is inferior and as an experiential reference it sets the threshold for what to expect. (Male, 21, during trial)

While this statement indicates retrospective reflexivity integrated with the emerging experience, the following illustrates post trial changes in expectancies of new $\mathrm{m}$-service incorporation:

Using the Internet a few years ago was a hassle too. Nowadays you take it for granted and just use it easy and as part of your everyday. I think much of that goes for the mobile. You really need to get your mind around it in order to get into using it. It takes a while. So, I have more realistic expectations and intentions now after the project. (Female 26, after trial)

\subsubsection{Reflexive Monitoring of M-Service Practices}

Participants in the field study also exhibited awareness and monitoring of both direct $m$-service practices, practices in which operation of $m$-services either have direct or mediating visibility toward others, as well as communicative m-service practices, expressions in which messages contain cues of m-services or use. In accordance with Giddens' (1984) argument that most of our daily behaviors are routine and, therefore, occur almost unconsciously unless something in the daily flow of activities is experienced to bring unanticipated consequences, we see that most comments relating to the domestication of new m-services stem from occurrences that are not in correspondence with previous routines.

I really had a hard time trying to send an MMS message. And I think I took quite some effort trying to find out about it. However, it was mentioned nowhere that I had to visit a web-page to get registered and obtain the configuration settings. That I found out about after having talked to my colleagues. (Male, 25, during trial)

Thus, although routines are most powerful as they reflect the practices that recur the most and thereby contribute most to the recursive ordering of $\mathrm{m}$-service practices across time and space, it is the little upheavals, such as the one described above, which seem to bring about unanticipated consequences and trigger acknowledgment of newness.

During the project, we also observed several participants belonging to the same cohort starting to use Bluetooth to transmit text and multimedia messages because they experienced that others had started doing so. The typical explanation was, "I started using Bluetooth because some of the others' started." Direct observation of others behavior thus seemed to provide cues into objectifying $\mathrm{m}$-services for the observer. 
I admit that the time that I have spent on playing with the "toy" in order to discover the hidden secrets is limited. What I have done is that I have looked over the shoulders of my mates when they have been playing and then tried to see how those services could be useful to me. However, the [name of portal] services are very slow-I have access to the internet everyday at work and if I need information that is where I would find it. (Female, 32, after trial)

Furthermore, reflexivity over influences of others' communicative actions, not only participants, but signals of $\mathrm{m}$-services in the surroundings offered stimuli for engaging in the assessment of motivations and rationalizations of the participant's own m-service agency.

Watching a commercial at the movie theater, I thought the services displayed seemed really smart. But then I started to think: Hey, wait a minute! That's what I have. That's what I don't use. It is mainly because it is too slow and too cumbersome. However, there are some services which can have value, but the value is too small compared to the efforts one must put into utilizing them.

(Male, 27, during trial)

\section{CONCLUSION AND NEXT STEPS}

Through an expanded, integrated framework of domestication and stratification, this paper has presented progress toward a process model introducing user reflexivity in the ongoing evolution of technology consumption. The rationale and theorizing underlying the process model has been illustrated through the results of a field study of new mobile service use. These results suggest that participants actively reflect on previous as well as emerging experiences and observations with related technologies, cues in social surroundings and $\mathrm{m}$-service actions, and that motivations as well as rationalizations indeed occur in a duration, a flow, influencing and revealing the degree of faithful, lasting, and extended appropriation. Hence, initial support has been provided that the monitoring of own and others' actions pertaining to m-services and related technologies, especially the Internet, unfold considerably after access to a technology has been gained. These observations are significant with respect to understanding dimensions of use beyond absolute points of acceptance and adoption; dimensions outside the reach of current technology acceptance research.

This paper has also illustrated that imaginative expectancies prior to trial, acceptance, and adoption can be intensely reconstructed, even deconstructed, during post trial, acceptance, or adoption periods. While existing research primarily views acceptance and adoption as absolute outcomes, this paper suggests that there is an array of potentially multifaceted outcomes which can determine not only the relative impact of a certain service or technology in everyday life, but also the relative impact of such outcomes on own and others' further m-service consumption. With the interdependent, varied, and compound smorgasbord of services offered, we contend that reflexivity during the domestication processes can yield unintended and unacknowledged conditions in user cognizance which can later become reflected in different degrees of patronizing m-service actions. 
Further research in this area could expand the exploration of the underlying characteristics of the reflexivity at different stages in the domestication process. This can provide insight into what specific properties, attributes, and practices appear to cause progression, digression, or seizure to the process as well as how different properties of $m$-services may become enacted in physical and virtual co-presence. If carefully attended to, this could reveal narratives and interactions pertaining to $\mathrm{m}$ service properties and their career over time and the meaning and impacts these properties may have in everyday life and in the continuing construction of meaning and practices during the unfolding of domestication. As such, we may avoid equating acceptance and adoption with continued everyday life use.

\section{ACKNOWLEDGMENTS}

This research was carried out in the realm of the Mobiconomy project at Copenhagen Business School. The research was in part supported by the Danish Research Agency, grant number \#2054-03-0004. The authors made equal contributions to the paper.

\section{REFERENCES}

Ajzen, I. "From Intentions to Actions: A Theory of Planned Behavior," in Action Control: From Cognition to Behavior, J. Kuhl, and J. Beckman (Eds.), New York: Springer, 1985.

Ajzen, I. "The Theory of Planned Behavior," Organizational Behavior and Human Decision Processes (50), 1991, pp. 179-211.

Ajzen, I., and Fishbein, M. Understanding Attitudes and Predicting Social Behavior, Englewood Cliffs, NJ: Prentice Hall, 1980.

Aune, M. "The Computer in Everyday Life: Patterns of Domestication of a New Technology," in Making Technology Our Own. Domesticating Technology into Everyday Life, M. Lie, and K. H. Sørensen (Eds.), Oslo: Scandinavian University Press, 1996, pp. 91-120.

Constantiou, I. D., Damsgaard, J., and Knutsen, L. A. "Strategic Planning for Mobile Services Adoption and Diffusion: Empirical Evidence from the Danish Market," paper presented at the IFIP TC8 Working Conference on Mobile Information Systems (MOBIS), Oslo, Norway, September 15-17, 2004.

Davis, F. D. "Perceived Usefulness, Perceived Ease of Use, and User Acceptance of Information Technology," MIS Quarterly (13:3), 1989, pp. 319-339.

DeSanctis, G., and Poole, M. S. "Capturing the Complexity in Advanced Technology Use: Adaptive Structuration Theory," Organization Science (5:2), 1994, pp. 121-147.

Fichman, R. G., and Kemerer, C. F. "The Assimilation of Software Process Innovations: An Organizational Learning Perspective," Management Science (43:10), 1997, pp. 1345-1363.

Fichman, R. G., and Kemerer, C. F. "The Illusory Diffusion of Innovation: An Examination of Assimilation Gaps," Information Systems Research (10), 1999.

Foxall, G. R., Goldsmith, R. E., and Brown, S. Consumer Psychology for Marketing ( ${ }^{\text {nd }}$ ed.), Oxford, UK: International Thomson Business Press, 1998.

Giddens, A. The Constitution of Society, Cambridge, UK: Polity Press, 1984.

Gopalakrishnan, S., and Damanpour, F. "A Review of Innovation Research in Economics, Sociology and Technology Management," Omega (25:1), 1997, pp. 15-28.

Haddon, L. "Domestication and Mobile Telephony," paper presented at the "Machines that Become Us" Conference, Rutgers University, New Brunswick, NJ, April 18-19, 2001. 
Haddon, L. Information and Communication Technologies in Everyday Life, Oxford, UK: Berg, 2004.

Hubona, G., and Burton-Jones, A. "Modeling the User Acceptance of E-Mail," paper presented at the $36^{\text {th }}$ Hawaii International Conference on Systems Science, Big Island, Hawaii, January 6-9, 2003.

Hughes, T. P. "The Evolution of Large Technological Systems," in The Social Construction of Technological Systems, W. E. Bijker, T. P. Hughes, and T. J. Pinch (Eds.), Cambridge, MA: MIT Press, 1987, pp. 51-82.

Khalifa, M., and Cheng, S. K. N. "Adoption of Mobile Commerce: Role of Exposure," paper presented at the $35^{\text {th }}$ Hawaii International Conference on System Sciences, Big Island, Hawaii, January 5-8, 2002.

Kirzner, I. M. "Entrepreneurial Discovery and the Compeititve Market Process: An Austrian Approach," Journal of Economic Literature (35:1), 1997, pp. 60-85.

Knutsen, L. A. "M-Services Expectancies and Attitudes: Linkages and Effects of First Impressions," paper presented at the $38^{\text {th }}$ Hawaii International Conference on Systems Science, Big Island, Hawaii, January 3-6, 2005.

Knutsen, L. A., and Overby, M. L. "Strategic Postures and Compound Product-Service Offerings: Supply and Demand-side Implications," paper presented at the International Conference on Mobile Business, New York, July 12-13, 2004.

Lamb, R., and Kling, R. "Reconceptualizing Users as Social Actors in Information Systems Research," MIS Quarterly (27:2), 2003, pp. 197-235.

Lee, A. S. "Integrating Positivist and Interpretive Approaches to Organizational Research," Organization Science (2:4), 1991, pp. 342-365.

Lehtonen, T. K. "The Domestication of New Technologies as a Set of Trials," Journal of Consumer Culture (3:3), 2003, pp. 363-385.

Lie, M., and Sørensen, K. H. Making Technology Our Own? Domesticating Technology into Everyday Life, Oslo: Scandinavian University Press, 1996.

Ling, R. The Mobile Connection: The Cell Phone's Impact on Society ( ${ }^{\text {rd }}$ ed.), San Francisco: Morgan Kaufmann Publishers, 2004.

Ling, R., and Haddon, L. "Mobile Telephony, Mobility and the Coordination of Everyday Life," paper presented at the "Machines that Become Us," Rutgers University, Camden, NJ, 2001.

Lu, J., Lie, C., Yu, C.-S., and Yao, J. "Exploring Factors Associated with Wireless Internet via Mobile Technology Acceptance in Mainland China," Communications of the International Information Management Association (3:1), 2003, pp. 101-120.

Lyytinen, K., and Damsgaard, J. "What's Wrong with the Diffusion of Innovation Theory? The Case of a Complex and Networked Technology," paper presented at the IFIP WG 8.6 Working Conference on Diffusing Software Product and Process Innovations, Banff, Canada, April 7-10, 2001.

Miles, M. B., and Huberman, A. M. Qualitative Data Analysis, Thousand Oaks, CA: Sage Publications Inc., 1994.

Miller, D. Material Culture and Mass Consumption, Oxford, UK: Blackwell, 1987.

Nokia Networks. "A History of Third Generation Mobile," White Paper, July 6, 2003 (available online at http://www.3gnewsroom.com/html/whitepapers/year_2003.shtml).

Pedersen, P. E., and Ling, R. "Modifying Adoption Research for Mobile Internet Service Adoption: Cross-Disciplinary Interactions, "paper presented at the $36^{\text {ll }}$ Hawaii International Conference on Systems Science, Big Island, Hawaii, January 6-9, 2003.

Pedersen, P. E., Methlie, L. B., and Thorbjørnsen, H. "Understanding Mobile Commerce EndUser Adoption: A Triangulation Perspective and Suggestions for an Exploratory Service Evaluation Framework," paper presented at the $35^{\text {th }}$ Annual Hawaii International Conference on System Sciences, Big Island, Hawaii, 2002.

Pinch, T. J., and Bijker, W. E. "The Social Construction of Facts and Artifacts: Or How the Sociology of Science and the Sociology of Technology Might Benefit Each Other," in W 
The Social Construction of Technological Systems, E. Bijker, T. P. Hughes, and T. J. Pinch (Eds.), Cambridge, MA: MIT Press, 1987, pp. 17-50.

Rogers, E. M. Diffusion of Innovations ( $4^{\text {th }}$ ed.), New York: The Free Press, 1995.

Rogers, E. M. Diffusion of Innovations ( $5^{\text {th }}$ ed.), New York: The Free Press, 2003.

Rohracher, H. "The Role of Users in the Social Shaping of Environmental Technologies," Innovation: The European Journal of Social Sciences (16), 2003, pp. 177-192,

Silverstone, R., and Haddon, L. "Design and the Domestication of Information and Communication Technologies: Technical Change and Everyday Life," in Communication by Design, R. Mansell, and R. Silverstone (Eds.), Oxford, UK: Oxford University Press, 1996, pp. 44-74.

Taylor, S., and Todd, P. A. "Understanding Information Technology Usage: A Test of Competing Models," Information Systems Research (6:2), 1995, pp. 144-176.

Van de Ven, A. H., and Rogers, E. M. "Innovations and Organizations: Critical Perspectives," Communication Research (15), 1988, pp. 15: 632-651.

Venkatesh, V., Morris, M. G., Davis, G. B., and Davis, F. D. "User Acceptance of Information Technology: Toward a Unified View," MIS Quarterly (27:3), 2003, pp. 425-479.

Wolfe, R. A. "Organizational Innovation: Review, Critique and Suggested Research Directions," Journal of Management Studies (31:3), 1994, pp. 405-432.

\section{ABOUT THE AUTHORS}

Jennifer Blechar holds an M.Sc. in Analysis, Design and Management of Information Systems from the London School of Economics and Political Science, UK, and a B.A. in Mathematics from Bryn Mawr College, USA. She is a Ph.D. candidate and research fellow with the Department of Informatics at the University of Oslo, Norway, and has several years experience as a consultant within the telecommunications field. Her research interests involve the design, implementation, and diffusion of high value content services in the mobile industry. Jennifer can be reached at jennifjb@ifi.uio.no.

Lars Knutsen is a Ph.D. scholar at the Department of Informatics at the Copenhagen Business School. He holds a Master of Marketing Management from the Norwegian School of Management and a Master of Science in Strategy from the Aarhus School of Business. His dissertation research analyzes meanings and actions emerging during people's earliest acquaintances with new wireless services and the properties and gratifications these meanings and actions signify. Lars can be reached at 1k.inf@cbs.dk.

Jan Damsgaard is professor at the Department of Informatics, Copenhagen Business School, Denmark. He holds a Master's degree in Computer Science and Psychology and a Ph.D. in Computer Science (1996). Jan is the study director of a graduate program in e-business. His research focuses on the diffusion and implementation of networked and standard-based technologies such as intranet, extranet, Internet portals, EDI, and advanced mobile services (GSM/ GPRS/EDGE, UMTS, WiFi, and WiMax). In much of his research, he seeks to explain technology innovation using network economics and technology characteristics. Jan is the research director of the Mobiconomy and DREAMS projects that focus on diffusion and implementation of advanced mobile services. He has presented his work at international conferences (ICIS, ECIS, PACIS, HICSS, IFIP 8.2. and 8.6) and in international journals (European Journal of Information Systems, Information Systems Journal, Journal of Strategic Information Systems, Information Society, Journal of Global Information Management, Journal of Organizational Computing and Electronic Commerce, Information Technology and People, and Journal of the Association for Information Systems). Jan can be reached at damsgaard@ cbs.dk or at http://www.cbs.dk/staff/damsgaard/. 